\title{
POLÍTICAS PÚBLICAS E GERENCIAMENTO DOS RECURSOS HÍDRICOS NA CIDADE DE TERESINA (PIAUÍ)
}

Tiago Caminha de Lima ${ }^{(a)}$; Albert Isaac Gomes Viana ${ }^{(b)}$; Hikaro Kayo de Brito Nunes ${ }^{(\mathrm{c})}$; Sara Raquel Cardoso Teixeira de Sousa ${ }^{(d)}$

(a) Mestre pelo Programa de Pós-graduação em Geografia/UFPI. E-mail: tiago_caminha@ @hotmail.com

(b) Mestrando do Programa de Pós-graduação em Geografia/UFPI. E-mail: xaigvx@ @mail.com

(c) Mestrando do Programa de Pós-graduação em Geografia/UFPI. E-mail: hikarokayo2@ hotmail.com

(d) Mestranda do Programa de Pós-graduação em Geografia/UFPI. E-mail: sararcts@ outlook.com

\section{EIXO: BACIAS HIDROGRÁFICAS E RECURSOS HÍDRICOS: ANÁLISE, PLANEJAMENTO E GESTÃO}

\begin{abstract}
Resumo
Teresina possui localização privilegiada, com quantidade significativa de rios (Parnaíba e Poti), riachos e lagoas, apresentando-se vulneráveis frente ao processo de urbanização causando grandes riscos à qualidade dos recursos hídricos. Diante disso, este estudo objetiva identificar e analisar de que forma as políticas públicas (municipais) voltadas aos recursos hídricos foram desenvolvidas no ano de 2013 na cidade de Teresina/PI. Para alcançá-lo, os procedimentos metodológicos foram: levantamento e análise de materiais teóricos, bibliográficos e documentais (incluindo leis e decretos), pesquisa de campo e realização de entrevistas junto a gestores públicos municipais. Por meio das entrevistas notouse a desarticulação das ações públicas nos referidos órgãos, mesmo estes possuindo as mesmas características e atribuições legais, diante disso, há a ausência ou diferenciação das políticas públicas nas quatro zonas administrativas da cidade, que, para alguns gestores, está associado a própria infraestrutura dos órgãos e a participação da sociedade nas discussões.
\end{abstract}

Palavras-chave: Recursos hídricos; Políticas públicas, Teresina/PI.

\section{Introdução}

Teresina (capital do estado do Piauí) possui uma situação privilegiada em relação à disponibilidade de recursos hídricos, pois se apresenta margeada por dois rios (Parnaíba e Poti) além de uma quantidade significativa de lagoas e riachos. No entanto, a cidade passa nas últimas décadas (19702010) por um intenso processo de urbanização e ascensão industrial, contribuindo com a degradação dos recursos hídricos, principalmente pela falta de planejamento urbano e ambiental.

Sabe-se, no entanto, que o aumento populacional em decorrência da expansão comercial e industrial é proporcional à demanda de água, ressalta-se assim, que em alguns pontos da cidade há a escassez de água em função do crescimento desordenado e pela falta ou ineficiência da aplicação de um sistema de gestão hídrica adequado. Destarte, esse trabalho aborda o tema sobre análise das políticas públicas municipais de Teresina em relação ao gerenciamento dos recursos hídricos. Nesse sentido, 
estudos envolvendo a ciência geográfica e recursos hídricos são necessários para uma melhor compreensão das atividades realizadas pela sociedade junto ao meio ambiente, em especial as águas.

Considerando o conjunto formado pelos de diversos autores, intepretação de leis ambientais (na esfera federal, estadual e municipal), o conhecimento sobre a atuação dos órgãos responsáveis pela preservação, educação e fiscalização do meio ambiente, especificadamente na área dos recursos hídricos, e a sociedade responsável direta na relação com os recursos hídricos, estabeleceu-se através desses, a ideia de Gestão Ambiental, que segundo Meyer (2000), o conceito está relacionado com o objetivo de manter a qualidade ambiental para atender as necessidades humanas atuais, de atuar sobre as modificações humanas causadas ao meio ambiente, da criação de instrumentos de monitoramento de atividades sobre o ambiente, além de estar relacionado com diagnósticos ambientais a partir de estudos e pesquisas dirigidos em busca de soluções para os problemas que forem detectados.

Neste escopo, o estudo teve como objetivo, identificar e analisar de que forma as políticas públicas (municipais) voltadas aos recursos hídricos estão sendo desenvolvidas na cidade de Teresina (Piauí).

\section{Aporte Teórico}

As leis foram elaboradas com a função de ajudar a organizar uma sociedade. Teresina possui sua própria lei orgânica (TERESINA, 2011) que faz referência a diversos temas de suma importância, que versam desde a educação, saúde, seguridade social dentre outros. Diante do atual contexto global e das discussões que envolvem a importância do uso consciente da água, a questão dos recursos hídricos também se faz presente na referida lei.

A lei orgânica do município de Teresina tem como objetivos fundamentais promover o desenvolvimento integral, potencializando seus recursos humanos e naturais juntamente com a preservação das condições ambientas adequadas à qualidade de vida e ao meio ambiente ecologicamente equilibrado, tendo em vista a necessidade de melhorar a qualidade de vida da população e do meio ambiente (TERESINA, 2011).

Quando se trata da relação entre urbanização e meio ambiente, nesse caso referente às lagoas, a lei proíbe a construção bem como o despejo de lixo, águas servidas ou de esgotos domiciliares nestes locais. Sendo permitida apenas a instalação de estabelecimentos a partir da apresentação de um projeto especifico, seguindo a legislação ambiental e sendo aprovado pela Câmara Municipal, a exemplo dos Estudos de Impacto Ambiental (EIA) e dos Relatórios de Impacto Ambiental (RIMA). 
Discutindo a relação recursos hídricos e degradação, Tundisi (2003) e Tucci (2008) elencam algumas formas de degradação, dentre elas, destacam-se os esgotos sanitários, os efluentes industriais, os esgotos pluviais, a impermeabilização do solo, as alterações antropogênicas no curso d'água e a retirada da mata ciliar, que, conforme Pagnoccheschi (2000) acaba por aumentar os custos do tratamento. Quanto às Políticas Públicas, Teixeira (2002) e Putti et al (2013) ressaltam que este é um termo recente no cotidiano por se tratarem de princípios norteadores do poder público, associados à regras e procedimentos mediando as relações entre Estado e sociedade.

Algumas colocações sobre os princípios e critérios relacionados a Política Nacional de Recursos Hídricos, segundo a Lei 9.433/97 (BRASIL, 1997, não paginado) é importante ressaltar nesta discussão. Além das contribuições do Ministério do Meio Ambiente (2006) ao compreender sobre os princípios, estratégias e diretrizes de atos e procedimentos para proteger a integridade do meio físico e biótico.

A partir desse contexto, passa-se a análise das ideias dos gestores locais referentes à política municipal de gerenciamento hídrico e suas implicações na sustentabilidade no espaço urbano. Partindo também do conhecimento crítico relacionado à gestão hídrica envolvendo a sustentabilidade defendida por diversos autores.

\section{Procedimentos Metodológicos}

A pesquisa se sustentou em três etapas, a primeira com o levantamento e análise dos dados documentais, teóricos e bibliográficos, a segunda com pesquisa de campo e a terceira com o tratamento e análise dos dados obtidos. Os procedimentos metodológicos se enquadram como pesquisa qualitativa e bibliográfica, que para Gil (2009) esta última se destaca na vantagem de residir no fato de permitir ao investigante a cobertura de uma gama de fenômenos muito mais ampla do que aquela que poderia pesquisar diretamente. Fez-se uso também de pesquisa documental baseada em levantamento e análise de leis federais, estaduais e municipais a respeitos dos recursos hídricos e do espaço urbano.

A posteriori, foi realizada pesquisa de campo (durante o ano de 2013) com realização de entrevistas junto aos gestores públicos municipais que trabalham com o gerenciamento ambiental, assim, possibilitando investigar de que forma as políticas públicas voltadas aos recursos hídricos estavam sendo desenvolvidas em Teresina. As entrevistas foram realizadas nas quatro Superintendências de Desenvolvimento Urbano (SDU's), onde estão instaladas as Gerências de Meio Ambiente (GMA's) das zonas Centro-Norte, Sul, Sudeste e Leste, além de entrevista na Secretaria Municipal de Meio Ambiente e Recursos Hídricos (SEMAM). 
A entrevista buscou ampliar as ideias somadas aos estudos bibliográficos e documentais a fim de verificar a atuação destes órgãos no espaço urbano teresinense. $O$ quadro 1 apresenta o perfil dos entrevistados, como: formação acadêmica, órgão e cargo de responsabilidade e a área abrangência na cidade. A partir do quadro abaixo e no decorrer das análises, nomearam-se os entrevistados pela nomenclatura de letras do alfabeto (A, B, C, D e E).

Quadro 1 - Perfil dos entrevistados

\begin{tabular}{|c|c|c|c|c|}
\hline ENTREVISTADO & ÓRGÃO & ÁREA DE ATUAÇÃO & ZONA & FORMAÇÃO \\
\hline "A" & GMA & Gerente de Meio Ambiente & Centro/Norte & Bióloga \\
\hline "B" & GMA & Gerente de Meio Ambiente & Sul & Gestora Ambiental/Bióloga \\
\hline "C" & GMA & Gerente de Meio Ambiente & Sudeste & $\begin{array}{c}\text { Bióloga e Mestre em } \\
\text { Desenvolvimento e Meio } \\
\text { Ambiente }\end{array}$ \\
\hline "D" & GMA & Gerente de Meio Ambiente & Leste & Engenheiro Civil \\
\hline "E" & SEMAM & $\begin{array}{c}\text { Gerente Executivo de } \\
\text { Meio Ambiente }\end{array}$ & $\begin{array}{c}\text { Todo o } \\
\text { município }\end{array}$ & $\begin{array}{c}\text { Engenheiro Agrônomo e } \\
\text { Especialista com MBA em } \\
\text { Gestão Ambiental e } \\
\text { Desenvolvimento Sustentável }\end{array}$ \\
\hline
\end{tabular}

Ressalta-se além do mais, que o município de Teresina está localizado no Centro-Norte do estado do Piauí e possui população estimada (segundo dados do IBGE) em 836.475 habitantes em 2013 e atualmente com 847.430 habitantes. A cidade possui um expansivo crescimento horizontal e vertical e sua área urbana é dividida administrativamente em quatro zonas, denominadas Superintendência de Desenvolvimento Urbano - SDU (Centro-Norte, Leste, Sudeste e Sul) conforme figura 1. 


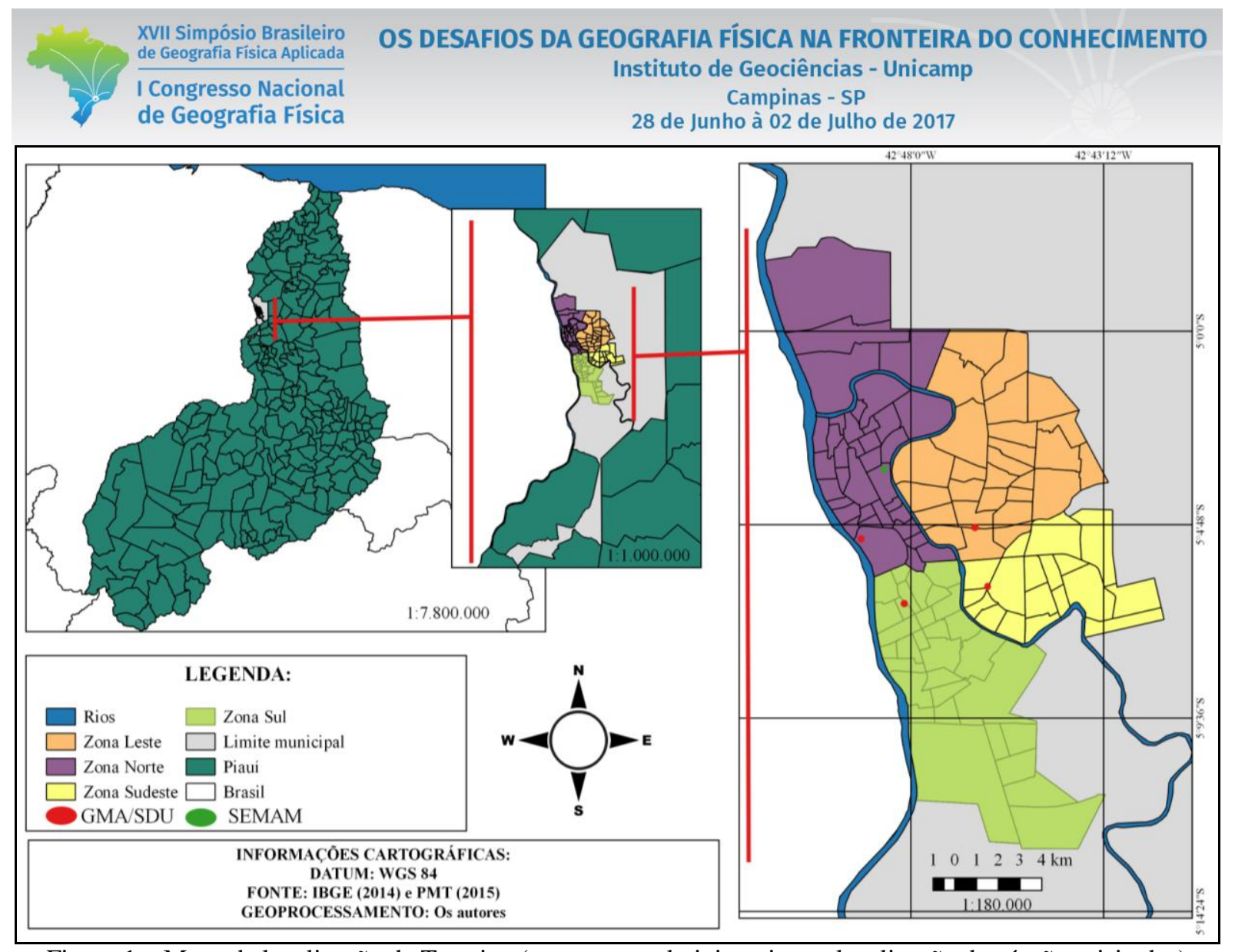

Figura 1 - Mapa de localização de Teresina (com zonas administrativas e localização dos órgãos visitados)

\section{Resultados e Discussão}

A Prefeitura Municipal de Teresina possui órgão específico para questões voltadas ao meio ambiente, no caso a Secretaria Municipal de Meio Ambiente e Recursos Hídricos (SEMAM), tendo sido criada através do decreto Lei $n^{\circ} 2.184$ de 14 de janeiro de 1993 e, com a sua extinção no ano 2000, foram criadas as GMA's que se localizam internamente nas estruturas das SDU's de cada zona da cidade. Afirma-se ainda que através do decreto Lei no 3.616/2007 a SEMAM é reinstalada com os objetivos principais de promover a educação ambiental, a preservação e a proteção do meio ambiente, o uso sustentável dos recursos naturais, a elaboração de diretrizes e o controle do crescimento urbano para o racional desenvolvimento do município de Teresina, além do planejamento e necessária articulação intersetorial com as demais secretarias municipais.

As ações e projetos desse órgão buscam controlar/minimizar os danos causados ao meio ambiente devido, principalmente relacionado aos despejos de gases poluentes na atmosfera, instalações ilegais de esgotos e ao grande acúmulo de lixos domésticos. Neste ínterim e na composição das equipes gestoras (das GMA's e da SEMAM) é necessária para a boa condução dos trabalhos uma equipe especializada e conhecedora da cidade, sobre isso, destaca Ferri, Luchi e Bellon (2010, p. 9), que as políticas públicas de 


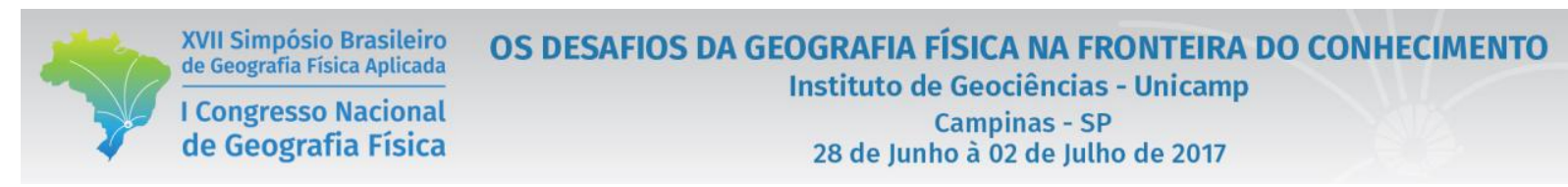

gestão “[...] têm por objetivo aprimorar a capacidade de formulação e implementação de políticas e tornar eficiente a gestão de recursos, para que o Estado possa atender cada vez melhor às demandas dos usuários por mais e melhores serviços públicos e participação da sociedade".

Assim, prevalece uma equipe de gestão concentrada em atividades voltadas a sua área de estudo, buscando melhorar o atendimento e o diálogo com a população na busca de aprimorar seus serviços. Nas informações colhidas através das entrevistas elencam-se as prioridades de cada órgão frente à problemática ambiental e de recursos hídricos na cidade além de retratarem a preocupação junto com a sociedade em fiscalizar, monitorar previamente a instalação e operação de empreendimentos para que não haja nenhum impacto significativo ao meio ambiente (quadro 2).

Quadro 2 - Prioridades da SDU (Gerência de Meio Ambiente) para a população.

\begin{tabular}{|c|c|}
\hline ENTREVISTADO & RESPOSTA \\
\hline "A" & $\begin{array}{l}\text { O bem estar da população com uma fiscalização e monitoramento dos empreendimentos } \\
\text { para que não haja nenhum impacto significativo no meio ambiente. }\end{array}$ \\
\hline "B" & $\begin{array}{l}\text { A GMA possui vínculo com a Secretária Municipal de Meio Ambiente e Recursos } \\
\text { Hídricos - SEMAM. As principais prioridades da GMA/Sul estão no licenciamento } \\
\text { ambiental, principalmente de empreendimentos, monitoramento ambiental, é feito pela } \\
\text { forma de denúncia por parte da população com relação a diversos danos. E as } \\
\text { averiguaçóes da poluição sonora despejam de dejetos em recursos hídricos (rios, } \\
\text { lagoas) e o corte de árvores. }\end{array}$ \\
\hline "C" & $\begin{array}{l}\text { Licenciamento Ambiental Empresas. Monitoramento e Fiscalizações Ambientais no } \\
\text { Ambito Geral e Educação Ambiental. }\end{array}$ \\
\hline "D" & $\begin{array}{l}\text { A GMA possui como prioridades o licenciamento ambiental prévio, instalação e } \\
\text { operação. }\end{array}$ \\
\hline "E" & $\begin{array}{l}\text { Mitigação dos impactos ambientais negativos. Criação e consolidação das áreas } \\
\text { existentes em Teresina. Educação Ambiental. }\end{array}$ \\
\hline
\end{tabular}

Destaca-se o papel da população na operacionalização do órgão, visto que a mesma é o sujeito ativo e passivo do meio ambiente, especificadamente dos recursos hídricos. Essa comunidade entra como meio de comunicação entre os recursos hídricos e o órgão gestor, qualificando os serviços prestados pela GMA, como expõe a Lei $\mathrm{n}^{\circ}$ 9.433/1997, no seu art. 32 em que é criado o Sistema Nacional de Gerenciamento de Recursos Hídricos, com os seguintes objetivos:

I - coordenar a gestão integrada das águas; II - arbitrar administrativamente os conflitos relacionados com os recursos hídricos; III - implementar a Política Nacional de Recursos Hídricos; IV - planejar, regular e controlar o uso, a preservação e a recuperação dos recursos hídricos; V - promover a cobrança pelo uso de recursos hídricos. (BRASIL, 1997).

Através das respostas e da lei anteriormente citada ficou verificado que as maiores prioridades dos respectivos órgãos junto à população estão no licenciamento, fiscalização e monitoramento ambiental 
visto o progressivo crescimento da cidade. Para a sensibilização da população possui um núcleo voltado à Educação Ambiental (EA). A esse respeito, torna-se fundamental a existência de projetos (em planejamento ou em execução) a respeito das questões ambientais, como apresenta as informações do quadro 3.

Quadro 3 - Projetos em planejamento e/ou execução

\begin{tabular}{|c|l|}
\hline ENTREVISTADO & \multicolumn{1}{|c|}{ RESPOSTA } \\
\hline "A" & $\begin{array}{l}\text { Não. Nesta gerência não tem, mas na SEMAM sim, como por exemplo, o projeto de } \\
\text { arborização de Teresina. }\end{array}$ \\
\hline "B" & $\begin{array}{l}\text { Não existe um projeto, porque a SEMAM não possui um corpo de funcionários que seja } \\
\text { efetivo, acaba-se implicando ao não desenvolvimento de um projeto. }\end{array}$ \\
\hline "C" & $\begin{array}{l}\text { Atualmente na Gerencia de Meio Ambiente Sudeste não possui nenhum projeto de } \\
\text { planejamento. Acredito que na SEMAM (Sede) existem alguns projetos para } 2013 . \\
\text { Favor entrar em contato com a mesma no Parque da Cidade na pessoa do assessor } \\
\text { técnico. }\end{array}$ \\
\hline "D" & $\begin{array}{l}\text { Sim. Atualmente possui uma emenda, conseguida através de um projeto, para o Parque } \\
\text { Floresta Fóssil. }\end{array}$ \\
\hline "E" & Sim. Encontra-se fase inicial de elaboração projetos voltado ao meio ambiente. \\
\hline
\end{tabular}

Verificou-se a falta de projetos, em ação ou em planejamento, em três órgãos, relatados por "A", "B" e "C", destacando a falta de infraestrutura administrativa e equipe técnica para a realização do mesmo. Já "D" relata a existência de projetos, no caso direcionado ao Parque Floresta Fóssil, área de atuação de responsabilidade do seu órgão e "E" expõe que existe projeto em fase inicial de elaboração pela secretaria. Para que o órgão público possa agir, primeiramente, este deve se atentar para a observância dos princípios e normas constitucionais junto à legislação federal, estadual e municipal. Na discussão posterior colocou-se em questão sobre a existência de área ou/e equipe responsável pelo meio ambiente e especificadamente dos recursos hídricos (quadro 4).

Quadro 4 - Existência de área/equipe responsável pelo Meio Ambiente e Recursos Hídricos

\begin{tabular}{|c|l|}
\hline ENTREVISTADO & \multicolumn{1}{c|}{ RESPOSTA } \\
\hline "A" & Para o Meio Ambiente sim. Para os recursos hídricos especificadamente não \\
\hline "B" & $\begin{array}{l}\text { A GMA/Sul está dividida na equipe de Monitoramento e Licenciamento Ambiental. Com } \\
\text { relação aos recursos hídricos a SEMAM não possui nenhum projeto ou trabalho } \\
\text { direcionado a essa área, a partir mais relacionada aos recursos hídricos está no } \\
\text { licenciamento de dragas, no caso do rio Poti estão presente cerca de 50 dragas no } \\
\text { entorno urbano. }\end{array}$ \\
\hline "C" & $\begin{array}{l}\text { Não. A equipe técnica da GMA Sudeste é composta por mim Gerente - Bióloga, Chefe } \\
\text { de Licenciamento Ambiental - Eng. Agrônomo e o chefe de Monitoramento Ambiental - } \\
\text { Gestão de Recursos Humanos. Executamos os Processos de Licenciamento Ambiental e } \\
\text { Monitoramento Ambiental. }\end{array}$ \\
\hline "D" & $\begin{array}{l}\text { Sim. A equipe está dividida em: chefe de licenciamento, monitoramento fiscal e o Núcleo } \\
\text { de Educação Ambiental - NEA. Para os recursos hídricos não existe. }\end{array}$ \\
\hline "E" & $\begin{array}{l}\text { Para o Meio Ambiente sim. Para os recursos hídricos não, mas existe uma parceira com } \\
\text { o Conselho Regional de Engenharia e Arquitetura - CREA. }\end{array}$ \\
\hline
\end{tabular}


A partir dos dados citados notou-se a presença, em todos os órgãos entrevistados, de uma equipe técnica responsável pelas questões do meio ambiente, entretanto, há a ausência de equipes voltadas a temática dos recursos hídricos, com exceção de um órgão que mantém parceria com o Conselho de Regional de Engenharia e Arquitetura (CREA) para substituir à precária infraestrutura, principalmente para as ações hídricas. No que concerne ao apoio de cada órgão em projetos de educação ambiental verificou-se concordância entre os entrevistados. O entrevistado "E" destaca que o relacionamento entre a SEMAM e a população, é realizado através de parcerias na execução de diversas atividades. Como exemplo foram expostos as seguintes:

- Gincana Socioambiental Lagoas do Norte com o objetivo de promover um trabalho de valorização dessa área protegida pelo poder público e sensibilização socioambientais da população e demais participantes;

- Seminário de Educação Ambiental - Projeto Liberdade e Saúde com o objetivo de capacitar professores na ajuda da educação ambiental, sendo realizados nas escolas da capital e do interior;

- Curso de Capacitação Ambiental, que promove a formação de pessoas para atuarem no processo de aplicação de políticas públicas relativas ao meio ambiente e promover a inserção da educação ambiental no currículo em parceira com a SEMAR e o IBAMA;

- Natal Natureza no qual é realizada a distribuição de mudas, brinquedos, palestras e a apresentação de peças teatrais com ênfase na educação e sensibilização para o meio ambiente;

- Teresina é o Bicho que é realizado no dia do animal, visando à conscientização em relação aos maus tratos a animais (silvestres e domésticos); e

- Recreação Ecológica que realiza a mobilização de escolas para proporcionar um melhor conhecimento, interação e preservação sobre o Parque da Cidade, promovendo uma educação ambiental.

"A" e "C" destacaram a importância do Núcleo de Educação Ambiental (NEA) como grupo responsável por desenvolver projetos voltados para as comunidades, desse modo, as políticas públicas voltadas para a área educacional são de grande relevância uma vez que trabalham com projetos de cunho ambiental capacitando indivíduos através de palestras e minicursos, além de utilizarem recursos junto à mídia para ajudar na sensibilização da população.

Quanto discutida a temática dos recursos hídricos, observou-se uma uniformidade dos entrevistados nas afirmativas de que se busca suprir o déficit de infraestrutura e gerenciamento dos recursos hídricos através de parcerias. Nesse aspecto "C" destacou que a GMA Sudeste analisa os processos de Licenciamento Ambiental (LA) e os possíveis impactos causados com a implantação de 
quaisquer empreendimentos relacionando-os com as questões de ordem ambiental na qual se insere os recursos hídricos. E "E” afirmou que as ações se sustentam no planejamento plurianual do órgão. Evidencia-se assim o papel das parcerias para o desenvolvimento de ações (proteção, inspeção e monitoramento) dos recursos hídricos. A mesma é de grande relevância, pois amplia as discussões hídricas para outros setores, antes não envolvidas. A partir dessa inclusão possam esta qualificando seus serviços e repensando o modo de atuação dos órgãos junto ao meio ambiente, em destaque aos recursos hídricos.

A disponibilidade de informações para a comunidade sobre a questão dos recursos hídricos foi um tema recorrente na entrevista, tendo sido discutido de maneira diferente pelos gestores. "A", "B" e "D" afirmaram existir acessibilidade a informações para comunidade. Enquanto "C" não soube informar sobre o questionamento e "E" afirmou que há a inexistência de um sistema informatizado, não havendo, um registro histórico de dados do monitoramento dos rios. Destaca-se a Lei Orgânica do munícipio de TERESINA (2011, p. 120), atualizada em através da emenda $n^{\circ}$ 19/2011, quando afirma que “o Município assegurará a participação das entidades representativas da comunidade no planejamento e na fiscalização da proteção ambiental, garantindo o amplo acesso dos interessados às informações sobre as fontes de poluição e degradação ambiental ao seu dispor".

No que se refere à existência de projetos de preservação e gestão hídrica participativa, "D" destacou que "a equipe técnica do órgão é bastante restrita" e "B", por sua vez, exaltou que "infelizmente não possuímos projetos específicos para recursos hídricos e no caso quem poderia ter projetos para essa área seria a Secretaria Estadual de Meio Ambiente e Recursos Hídricos (SEMAR)”. Acredita-se que, por ser um tema tão relevante e fundamental para discussões entre os poderes há a necessidade de parcerias como indica TERESINA (2011, p. 119) "para assegurar efetivamente esse direito, o Município deverá articular-se com os órgãos estaduais, regionais e federais competentes e, quando for o caso, com outros Municípios, objetivando a solução de problemas comuns relativos à proteção ambiental”.

É aparente a falta de articulação com os demais órgãos, citados por "B”, na elaboração de projeto, sendo visível também através de sua afirmação constatar a falta de projetos direcionados as águas, ainda afirmando um "jogo de passa bola" (palavras do entrevistado) entre as principais entidades responsáveis em gerir, fiscalizar e proteger os recursos hídricos. Nesse questionamento apontam-se ações de sensibilização da população na preservação dos recursos hídricos. $\mathrm{O}$ manifesto dos entrevistados é igualitário, enfatizando as ações do NEA, que destacou "B", ao colocar que "dentro da SEMAM possui uma equipe especializada, que é o Núcleo de Educação Ambiental-NEA, são pessoas formadas na área ambiental, realizam palestras para faculdades, escolas, comunidade e a utilização de folders, panfletos, 
propagandas por meio da televisão, rádio, outdoor". Corroborando o exposto por " $\mathrm{D}$ " do papel do referido Núcleo, em "gerir através de campanhas de Educação Ambientais, palestras e seminários ações de sensibilizar a população na preservação do meio ambiente”.

A respeito do monitoramento e controle de possíveis impactos da atividade humana sobre os recursos hídricos, visto que a cidade de Teresina passa por intensos problemas que agravam os problemas nos dois rios e nas inúmeras lagoas. Vieira (2000) destaca que o agravamento é ainda maior devido ao mau uso do solo e o acelerado desmatamento ocorrido nessas regiões e ao crescente aumento de resíduos desenvolvidos nas suas bacias, principalmente de esgotos domésticos, esgotos industriais, matadouros e lixos.

Verificou-se uma posição semelhante dos entrevistados quanto ao monitoramento, controle e fiscalização dos recursos hídricos. Para "A”, o "órgão fiscaliza as empresas que despejam os resíduos nos rios, como também o funcionamento das dragas, além da fiscalização e monitoramento das oficinas e empresas de ônibus". "C" ressalta a existência de vistorias e fiscalizações mensais e/ou anuais dos empreendimentos novos e os já instalados. Há ainda na Lei Orgânica, que o município deve participar do registro, acompanhamento e fiscalização das concessões de direitos de pesquisas e exploração dos recursos minerais e hídricos em seu território, conforme previsto no artigo 23, capítulo XI, da Constituição Federal e artigo 14, capítulo II, da Constituição Estadual. Segundo "E”, que a partir de 2013 seria realizado com o cadastro e contratação de um laboratório pela SEMAM para coletar e analisar dados em relação aos recursos hídricos.

No que diz respeito ao acompanhamento das políticas públicas direcionadas aos recursos hídricos, houve disparidades quanto às respostas dos entrevistados. Segundo "A", "C" e "E" esse acompanhamento não se confirma. Enquanto "D" e "B" destacaram a consolidação dessas políticas públicas na participação de conferências, realização de eventos/palestras e de atividades de EA, bem como em reuniões com o Ministério Público e outros órgãos. Assim, é notável a ausência da utilização das leis somada à gestão dos órgãos e da sociedade. Em virtude que os gestores, em sua maioria, não aproveitarem as políticas para ampliar a fiscalização, monitoramento e preservação do meio ambiente, em especial os recursos hídricos. Sobre o melhor aproveitamento dos recursos hídricos os gestores esboçaram desejos por melhorias na infraestrutura de seus respectivos órgãos e a participação ativa da população quanto a projetos ou propostas de proteção dos recursos hídricos (quadro 5).

Quadro 5 - Sugestões para melhor aproveitamento e proteção dos recursos hídricos.

\begin{tabular}{|c|l|}
\hline ENTREVISTADO & RESPOSTA \\
\hline "A" & A criação de uma equipe técnica especializada na área. \\
\hline "B" & A sugestão principal, em minha opinião, é cada gerador seja responsável, tanto por seus \\
\hline
\end{tabular}




\begin{tabular}{|l|l|}
\hline & $\begin{array}{l}\text { resíduos líquidos ou sólidos. Onde cada empresa, indústria tem que possuir uma estação } \\
\text { de tratamento, assim como atualmente que todo loteamento é necessário ter uma estação } \\
\text { de tratamento. }\end{array}$ \\
\hline "C" & Maior fiscalização nos empreendimentos que usam inadequadamente o recurso. \\
\hline "D" & A sensibilização da população, visto que cada lugar possui seu aspecto cultural. \\
\hline "E" & Cada pessoa deve executar seu papel. Conscientizando aquilo que faz. \\
\hline
\end{tabular}

Assim, ressaltam-se os fundamentos, objetivos e diretrizes propostas nas leis federal, estadual e municipal na execução das leis vigentes que enfatizam a participação das comunidades no gerenciamento dos recursos hídricos. Assim, há a necessidade de ampliação da infraestrutura dos órgãos responsáveis pela gestão hídrica, ocasionada por diversos fatores, entre eles, o expansivo crescimento da cidade de Teresina, como também se indica a capacitação dos funcionários destas instituições para melhor atender a população. Sugere-se ainda um esforço na ampliação de ações de educação ambiental junto à comunidade voltadas para uma maior atenção com os recursos hídricos locais.

\section{Conclusão}

Diante da realização da pesquisa de campo ficou evidenciada a desarticulação entre os órgãos municipais responsáveis pelo gerenciamento dos recursos hídricos em Teresina.

A sociedade, através de seus representantes, promulgaram leis determinadas para os recursos hídricos. Visto que, os mesmos são de extrema importância para o desenvolvimento econômico, social, político e cultural da população. O papel das politicas públicas está em prevenir possíveis danos ao meio ambiente, fiscalizar e monitorar a execução das leis. Assim, as leis buscam pela gestão participativa, em que a comunidade, poder público e privado possam está convivendo em parceira para efetivar esses princípios.

Analisando as propostas dos órgãos, em termos das modalidades das políticas públicas, é possível concluir que apesar do otimismo no engajamento das instituições em relação à responsabilidade ambiental, ficam pendentes algumas questões que merecem maior reflexão, tais como: a participação da comunidade na discussão de propostas voltadas para os recursos hídricos, a execução das leis vigentes, a ampliação da infraestrutura dos órgãos responsáveis pela gestão hídrica e a capacitação dos funcionários destas instituições.

Nesse sentido, passa-se a vislumbrar como meta a educação ambiental para a sustentabilidade recuperando o significado do ecodesenvolvimento como um processo de conservação do meio natural e cultural que, por meio de técnicas apropriadas, impede desperdícios e realça as potencialidades destes meios, cuidando também da satisfação das necessidades de todos os membros da sociedade. Dessa forma, 
acredita-se que o Estado atuante em consenso com políticas públicas comprometidas com o bem-estar da população e do meio envolvente trarão resultados eficazes, como a recuperação de trechos desmatados ou ainda revitalização de áreas com grande quantidade de lixo.

\section{Referências}

BRASIL. Constituição Federativa do Brasil. Lei n ${ }^{\circ}$ 9.433, de 8 de janeiro de 1997. Política Nacional de Recursos Hídricos. Brasília: Governo Federal, 1997.

Ministério do Meio Ambiente. Secretaria de Recursos Hídricos. Caderno da Região Hidrográfico do Parnaíba. Brasília: MMA, 2006.

FERRI, M. B. R.; LUCHI, R. M.; BELLON, S. H. A construção do modelo de capacitação do gestor público estratégico do Espírito Santo: um novo olhar para o desenvolvimento gerencial. In: CONGRESSO CONSAD DE GESTÃ̃ PÚBLICA, 3., 2010, Brasília. Anais... Brasília, 2010.

GIL, A. C. Como Elaborar Projetos de Pesquisa. São Paulo: Atlas, 2009.

VIEIRA, V. P. P. B. A Água e o Desenvolvimento Sustentável no Nordeste. Brasília: IPEA, 2000.

TERESINA. Prefeitura Municipal de Teresina. Lei Orgânica do Município. Texto atualizado até a Emenda 19/2011. Teresina: Câmara Municipal de Teresina, 2011. 138 p.

TUNDISI, J. G. Água no século XXI: enfrentando a escassez. São Paulo: RiMA, IIE, 2003.

PUTTI, F. F. et al. Políticas públicas dos recursos hídricos no desenvolvimento da agricultura irrigada. Fórum Ambiental da Alta Paulista, v. 9, n. 7, 2013.

TEIXEIRA, E. C. O papel das políticas públicas no desenvolvimento local e na transformação da realidade. AATR-BA, 2002.

TERESINA. Prefeitura Municipal de Teresina. Lei Orgânica do Município. ed. rev., ampl. e consol. - Teresina: Câmara Municipal de Teresina, 2011. 138 p. Texto atualizado até a Emenda 19/2011.

TUCCI, C. E. M. Águas urbanas. Estudos Avançados. v. 22, n.63, 2008.

PAGNOCCHESCHI, B.. A Política Nacional de Recursos Hídricos no cenário da integração das políticas públicas. In: MUÑOZ, H. R. (Org.). Interfaces da Gestão de Recursos Hídricos: Desafios da Lei de Águas de 1997. Brasília: Secretaria de Recursos Hídricos, 2000.

MEYER, M. M. Gestão ambiental no setor mineral: um estudo de caso. 2000. Dissertação (Mestrado em Engenharia da Produção) - Universidade Federal de Santa Catarina, Florianópolis. 